\title{
Gender and Work Hours Transitions in Australia: Drop Ceilings and Trap-Door Floors*
}

\author{
Robert Drago, David Black and Mark Wooden \\ Melbourne Institute of Applied Economic and Social Research \\ The University of Melbourne
}

Melbourne Institute Working Paper No. 11/04

ISSN 1328-4991 (Print)

ISSN 1447-5863 (Online)

ISBN 073403153 X

July 2004

\begin{abstract}
* This paper reports on research being conducted as part of the research program, "The Dynamics of Economic and Social Change: An Analysis of the Household, Income and Labour Dynamics in Australia Survey". It is supported by an Australian Research Council Discovery Grant (DP0342970). The paper uses the data in the confidentialised unit record file from the Department of Family and Community Services' (FaCS) Household, Income and Labour Dynamics in Australia Survey, which is managed by the Melbourne Institute of Applied Economic and Social Research. The findings and views reported in the paper, however, are those of the authors and should not be attributed to either FaCS or the Melbourne Institute. Financial support for Robert Drago's travel and accommodation was also provided by the Faculty of Economics and Commerce at the University of Melbourne.
\end{abstract}

Melbourne Institute of Applied Economic and Social Research

The University of Melbourne

Victoria 3010 Australia

Telephone (03) 83442100

Fax (03) 83442111

Email melb-inst@unimelb.edu.au

WWW Address http://www.melbourneinstitute.com 


\begin{abstract}
We introduce the ideas of "drop ceilings", that full-time employees who switch to reduced hours thereafter face an hours ceiling such that a return to full-time employment is difficult, and of "trap-door floors", that full-time employees may be denied the opportunity to reduce their hours and instead face a choice between full-time employment and quitting the job. These ideas derive from the potential existence of norms around the ideal worker and motherhood. Relevant hypotheses are developed and tested using information on usual and preferred working time from the first two waves of the Household, Income and Labour Dynamics in Australia survey. The key findings are that women face drop ceilings significantly more often than men; that professionals and managers confront trap-door floors significantly more often than employees in other occupations; and that trap-door floor effects are generally stronger than drop ceiling effects in the data.
\end{abstract}




\section{Gender and Work Hours Transitions in Australia: Drop Ceilings and Trap-Door Floors}

Part-time employment may be inviting at certain stages in the life course, as when child or elder care responsibilities emerge, or as a form of phased retirement. At other stages, when employees are younger, or as child or elder care commitments dissipate, full-time employment may be more desirable. This paper was motivated by a suspicion that, among mothers whose children are growing up and achieving independence, attempts to switch from part-time to fulltime employment may prove difficult.

If the latter problem exists, it could be attributable to what we here label "drop ceilings". The notion of drop ceilings stems from the possibility that employees who choose part-time employment are stigmatized as non-ideal workers (Williams 1999), and subsequently constrained by their employer to part-time employment. That is, an upper limit on work hours may fall into place when employees enter part-time status, and the limit may be applied particularly to women. A longitudinal analysis of British data (Boheim and Taylor 2004) is consistent with this possibility: 30.5 percent of part-time employed women who desired longer hours had, by one year later, left their employer. This figure compares to only 23.3 percent of part-time employed women who were satisfied with their hours leaving their employer a year later. Further, almost twice as many of the prior group had switched employers in the process (10.9 compared to 6 percent), and had increased their hours substantially in the process. ${ }^{1}$

In Australia, recent cases surrounding legal protections for employees with caring responsibilities have raised a distinct but related possibility: difficulties faced by full-time employed women who seek to scale back work hours following the birth of a child (Bourke 2004). That is, a full-time employed professional woman who asks for reduced hours may find her superiors demanding that she remain full-time, effectively placing a floor under full-time hours. The woman is therefore constrained to either working full-time or quitting her job, in the

\footnotetext{
${ }^{1}$ The 30.5 and 23.3 percent figures are calculated by summing percentages across rows in Table 3 in Boheim and Taylor (2004). Increases in hours can be inferred from Table 6, although that table does not report separate results for full- and part-time employees. Note the British Household Panel Survey includes a question on whether employees wish to decrease, increase or keep their working hours about the same. The survey does not ask employees to specify preferred work hours, as in the HILDA. We are not aware of any other large panel data set including work hours preferences.
} 
latter case dropping through a "trap-door" in the floor. If either drop ceilings or trap-door floors exist, we expect they will affect women more than men because of norms around motherhood.

We develop these ideas and provide tests below for hypotheses relevant to drop ceilings and trap-door floors using data from the first two waves of the longitudinal Household, Income and Labour Dynamics in Australia (HILDA) Survey. This survey provides information on both usual and desired working time and so is ideal for testing these hypotheses.

\section{Theory and Previous Findings}

The theoretical underpinnings for the notions of drop ceilings and trap-door floors lie in the norms of the ideal worker and of motherhood. Williams (1999) argues that professional employees in the U.S. have experienced a diffusion of the ideal worker norm in recent decades. An ideal worker is someone who obtains relevant career credentials, moves immediately into employment, and works long hours with few interruptions for periods of years or even decades. As a norm, individuals who function as ideal workers expect such behavior of themselves and of others. Rewards such as high pay, promotions, and high status are reserved for those who most closely fit the norm. Historically, the ideal worker norm was applied to men, but the movement of women into professional careers led to its application to them as well.

Evidence supporting the diffusion of the ideal worker norm among professionals appears in studies showing that the prevalence of very long hours jobs has increased in recent decades, both in the U.S. (Jacobs and Gerson 2004) and in Australia (Wooden 2001). Most directly, Costa (2000) found that, between 1973 and 1991, the daily work hours of U.S. employees in the highest wage decile climbed by one-half hour for men, and by over half-an-hour for women. The spread of the ideal worker norm can help to explain why work hours increased for the most highly paid segment of the workforce.

The norm of motherhood is far older, and leads women to expect and be expected to provide unlimited care to dependents, and particularly to their own children, without remuneration (Williams 1999; Folbre 2001). Historically, in both the U.S. and Australia, the motherhood norm was linked to a "traditional" family structure, wherein the father served as a breadwinner and the wife performed unpaid work in the home (Moen 2002).

Women entered the paid labor force in large numbers in both countries in recent decades. In the U.S., data from the Bureau of Labor Statistics show adult women's labor force 
participation rate rising from 37.7 percent in 1960, to 60.2 percent in 2000 (Fullerton 1999). The earliest figures for women in Australia, collected by the Australian Bureau of Statistics, are for 1965, when 34.1 percent of adult women were employed, a figure that rose to 54.7 percent by $2000 .^{2}$

Theoretically, it was possible that women's entry into the labor force would have led to improved levels of gender equity in the home. Men might have reduced their work hours and performed more housework and child care as their wives entered paid employment. Egalitarian families, with equality both in paid work hours and in hours of unpaid work in the home, might have eventuated. This outcome did not in fact occur for a majority of families in Australia or the U.S. What happened instead was that the "neotraditional" family became the modal form for married couples with children both in the U.S. (Moen 2002) and in Australia (Drago, Tseng and Wooden 2004). In these families, the woman is employed, but the man works far more hours for pay, and the woman performs most unpaid work in the household, thereby sustaining a slightly softened form of gender inequality in both the home and the workplace.

The emergence of the neotraditional family can in part be attributed to the diffusion of the ideal worker norm. To the extent rewards in terms of pay, promotions and working conditions are reserved for those who best fit the ideal worker norm, married couples with children will find it advantageous for one member to serve as an ideal worker while the other works reduced hours. The gendered character of the ideal worker norm and, particularly, the motherhood norm informs us as to who is likely to function as an ideal worker - the man - and who will work reduced hours - the woman.

Life course considerations have a strong bearing on the ability of families to provide paid work hours (Moen 2002). Work hours are typically short or nonexistent while studying, but lengthen as school ends and prior to childrearing. Once childrearing responsibilities arise, time for those responsibilities becomes important, and desired work hours may decline. As children grow and typically leave home, caring responsibilities may lessen and desired work hours rise, though responsibilities for disabled elders or partners may emerge and effectively counteract any increase in desired hours at that time. Finally, desired hours may decline as retirement nears. We therefore expect that part-time employment for women will occur more frequently when

\footnotetext{
${ }^{2}$ These and other ABS figures drawn from the ABS world-wide web site, 10 June, 2004 [www.abs.gov.au].
} 
caring responsibilities are significant, and that preferences for part-time employment will vary over the life course with unpaid care commitments and ultimately with age.

Previous research indeed finds part-time employment closely correlated with motherhood. Studies of European Union nations (Tijdens 2002), of the U.S. (Blank 1994) and of Australia (Bardoel, Tharenoux and Ristov 2000) all find motherhood closely linked to part-time employment. ABS estimates for March 2004 show 6.9 percent of employed fathers, but 55.3 percent of employed mothers, working part-time. ${ }^{3}$ Among non-parents, 20 percent of men and 39.1 percent of women were employed part-time.

Given the norms discussed above, we can generate the notion of drop ceilings. The logic here is that employees who reduce their hours from full-time to part-time have signaled to the employer that they no longer strive to achieve ideal worker performance. Hence, ideal worker jobs, and their attendant long hours, may no longer be available to these employees. Drop ceilings should affect women more than men since motherhood (as opposed to fatherhood) is viewed as a signal of placing a high value on unpaid work in the home, further undercutting ideal worker appearance.

Trap-door floors may also exist for ideal workers, such that reduced hours jobs are not made available to them. Employees who wish to scale back hours are here given the choice of performing as an ideal worker or quitting the job, thereby dropping through a long-hours floor with no hope of return within the organization. In these cases, the ideal worker norm is so strong that even an individual whom the firm has trained, and who has performed well in the past, is viewed as having a negative net value if they work reduced hours. Again, we expect the phenomenon to affect women more strongly than men, since a man is more likely to be viewed as an ideal worker even if reduced hours employment is provided. Therefore, we can initially cast our argument in terms of gender differences:

Hypothesis 1. Drop ceilings (trap-door floors) exist such that part-time (full-time) employed women find it more difficult than men to increase (reduce) their work hours when they so desire.

\footnotetext{
${ }^{3}$ The definition of part-time employment used by the ABS is someone who usually works less than 35 hours per week and did so during the survey reference week (or were not at work during the survey reference week).
} 
The discussion to this point is mainly in the context of professional careers, particularly with regard to the ideal worker norm. By implication, drop ceilings and trap-door floors should appear more strongly for employees in professional and managerial occupations. Therefore:

Hypothesis 2. Drop ceilings (trap-door floors) exist such that managerial and professional employees who are employed part-time (full time) will find it more difficult than others to increase (reduce) their work hours when they so desire.

The discussion, and especially that surrounding the motherhood norm, also implies that Hypothesis 2 will be more relevant to women such that:

Hypothesis 2a. Drop ceiling and trap-door floor effects for women in managerial and professional occupations will be stronger than for comparable men.

As an empirical matter, employees may change employers in response to the existence of drop ceilings or trap-door floors. That is, if a part-time (full-time) employee wishes to increase (reduce) work hours, and these phenomena exist in the workplace, finding a new employer offering more satisfactory hours may resolve the problem. It is therefore important for hypothesis testing to control for respondents who change jobs so we do not attribute any related change in hours to the original employer allowing the shift. Further, if these phenomena affect women more strongly than men, we would predict that they will more often be driven to change employers in order to achieve their desired hours:

Hypothesis 3. Drop ceilings (trap-door floors) exist such that part-time (full-time) employed women will change employers more frequently than men in order to increase (reduce) their work hours when they so desire.

The notion of bias avoidance may also be relevant here. Drago and Colbeck (2003) argue that professional employees often strive to hide or minimize caregiving commitments from their employer and co-workers to prevent the incurring of career penalties due to biases against caregiving. In the present case, bias avoidance might take the form of full-time employees 
desiring but not asking for reduced hours in order to meet caregiving responsibilities. By implication, even if we find evidence supporting the existence of trap-door floors underneath full-time employees, employers might not have explicitly imposed the condition.

Further, to the extent drop ceilings and trap-door floors exist, these could even be viewed as evidence of bias against caregiving. Employees with caregiving commitments (particularly mothers) are locked into marginal, part-time jobs, while full-time employees who take on care commitments are either expected to continue as if they are unencumbered by family responsibilities or to quit. Employees therefore have an incentive to engage in bias avoidance by hiding any caregiving commitments from their employer and co-workers. Taken together, these arguments suggest Hypotheses 4 and 4a.

Hypothesis 4. Drop ceilings (trap-door floors) exist such that part-time (full-time) employees with caregiving commitments will find it more difficult than others to increase (reduce) their work hours when they so desire.

Hypothesis 4a. Drop ceiling and trap-door floor effects for women with caregiving commitments will be stronger than for comparable men.

The potential for bias avoidance makes our expectations regarding Hypothesis 4 weaker than for Hypotheses 1 thru 3. Hypothesis 4 requires that the employer knows about the caregiving commitments of employees, but bias avoidance suggests that such information will often be hidden by employees.

Beyond norms, incentives and labor market regulations play a role in determining the extent of part-time employment. For example, Buddelmeyer, Mourre and Ward (forthcoming) found for a sample of European Union nations that rates of part-time employment across the countries, and particularly changes in rates of part-time employment within countries, are highly responsive to shifts in public policies. Earnings thresholds for families to receive social insurance payments or to make contributions, tax incentives for employers to hire part-time employees, and wage equality policies for part-time employees can each affect rates of part-time employment. 
In the U.S., part-time employees typically receive a significantly lower hourly wage, and are less likely to receive employer-funded health insurance relative to full-time employees. ${ }^{4} \mathrm{By}$ way of contrast, Australia passed comparable worth wage legislation in the early 1970s (Gregory and Duncan 1981). These laws made it difficult for employers to pay lower wages for otherwise similar paid work that happens to be part-time. In addition, Australia has a single-payer health care system such that all residents have health care coverage regardless of employment status. Both wage equity and universal health insurance thus make part-time parity more of a reality in Australia.

Somewhat differently, most part-time employees in Australia are classified as "casuals" rather than "permanent" employees. In Australia the casual employment concept is a creation of its multi-employer awards system. That is, most awards - formal documents that are made, or assented to, by industrial tribunals and set out legally enforceable terms and conditions of employment - provide for a category of employment known as casual employment. ${ }^{5}$ As noted in Wooden and Warren (2004), however, "the definitions of casual employment that can be found in awards ... are extremely varied and in many cases provide little guidance as to the employment conditions that define casualness". Nevertheless, it is generally accepted that most casual employees are excluded from any entitlement to paid holidays, annual leave or sick leave, and in lieu of such benefits are provided a loading (typically 20 per cent) on their hourly wage.

Given the close connection between part-time and casual employment, an employee seeking to move from part-time to full-time status within the firm will frequently also be asking for a switch from casual to permanent status. For the employer, such a switch may imply that leave entitlements and permanent status will need to be provided, so the employer may have a financial incentive to constrain the employee to casual - and part-time - status. That is, the organization might save some money by implementing a drop ceiling such that part-time employees are denied the opportunity to obtain full-time, permanent status. By the same logic, organizations have an incentive to provide any employee who holds full-time, permanent status with opportunities to move to part-time, casual status, and thus avoid trap-door floor policies. These incentives suggest that part-time employees who are also casual may face stronger drop

\footnotetext{
${ }^{4}$ For pension and health care differences, see Drago (2000) or Williams (1999). For the part-time hourly wage penalty, see Budig and England (2001).

${ }^{5}$ Recent data on the coverage of employees by awards is scant. One estimate, however, suggests that 86 per cent of employees in non-farm organizations with 5 or more employees were, in 1999, still covered by a registered industrial award or agreement (Joint Governments Submission 2000, Table 5.4).
} 
ceilings. However, we cannot know from the data whether an increase in hours would in fact involve a switch to permanent status, so make no strong predictions here.

For comparative purposes, the facts just outlined suggest that, relative to a full-time employee, the costs of a part-time employee are higher in Australia relative to the U.S. In the latter country, moving an employee from part-time to full-time may involve the addition of health care and pension benefits and higher hourly wages as well; none of these additional costs would be incurred in Australia. Therefore, the incentives to implement a drop ceiling and keep part-time employees locked into part-time employment are stronger in the U.S., while the incentives to implement a trap-door floor and keep full-time employees locked into full-time employment are stronger in Australia. Unfortunately, this supposition cannot be tested until data comparable to the HILDA are created for the U.S.

Bargaining power might also play a role here. Note that bargaining power considerations run contrary to Hypothesis 2: professional and managerial employees should hold greater bargaining power than other employees, hence find it easier to increase or reduce their hours, and not more difficult as hypothesized. This possibility highlights yet again the importance of norms in driving the phenomena.

Bargaining power might also vary with age, rising as the employee ages and enters the prime earnings years, and dwindling as retirement nears. This argument suggests that drop ceiling and trap-door floor effects may be weaker during prime earnings years (e.g., ages 30 to 50). However, these are also the years when we would expect the ideal worker norm to be applied most strongly; young employees and those nearing retirement may be treated with greater emphathy and a lesser presumption that they are and should function as ideal workers. Therefore, although we do not make any strong predictions regarding age, it will be informative to test for any relevant effects.

Related to bargaining power is the issue of union membership. Historically, Australian unions, like their U.S. counterparts, promoted full-time employment with breadwinner wages for men (Davis and Lansbury 1998). That situation, however, may have changed with the entry of women into the Australian labor market, and resulting efforts to draw women into union membership. To the extent the earlier stance was maintained, we would expect that unions will be associated with trap-door floors, denying employees the opportunity to work reduced hours. 
To the extent unions have shifted in response to the preferences of their members, unions should be ameliorating constraints surrounding drop ceilings and trap-door floors.

Employment strategies might also be expected to vary between private and public sector employers and with organization size. Governments sometimes attempt to be model employers, suggesting in this case that public sector employment will be associated with reductions in the strength of drop ceiling or trap-door floor effects. On the other hand, the public sector might involve high levels of bureaucracy, making alterations in working time more difficult.

Somewhat differently, non-profit organizations might use working time flexibility as a device to attract employees, or find themselves so strapped for resources that it is in fact more difficult for them to offer flexibility. We therefore make no strong predictions on the effects of employment in the public or non-profit sector, but nonetheless test for a relationship.

The size of the workplace may also affect the ability of an employee to shift work hours. A small workplace may be less bureaucratic and hence more amenable to changes in work hours, but it might be more difficult to substitute one employee's time for another's in small workplaces. Somewhat differently, large organizations (as distinct from large workplaces) may be more bureaucratic, so less likely to provide work hours flexibility, or they might have greater resources to manage such changes. Again, we therefore test for the existence of relationships, but do not provide hypotheses here ex ante.

Finally, self-employment could be viewed as a device for achieving hours flexibility and escaping drop ceiling and trap-door floor effects. Indeed, it might be argued that if we discern a significantly enhanced ability for the self-employed to alter their work hours as desired, this would represent confirmation of drop ceilings and trap-door floors among employees proper. This argument fits the claims of those who believe that self-employment improves opportunities (presumably for women) to balance work and family commitments (e.g., Berke 2003). Nonetheless, self-employment does not occur in isolation, since starting an automobile factory in one's garage is no longer the option it once was. Instead, self-employment may be largely limited to certain occupations and industries which, in turn, might largely determine working time arrangements, as would be true for a restaurant or hotel owner. We therefore test for the effects of self-employment, but do not place great theoretical weight on the results.

A prior question for our analysis is why employees wish to change their hours. Life course considerations may provide part of the answer. As children age, as the number of 
dependent children in the home dwindles, or as elder care responsibilities wane, preferences among part-time employees for longer hours may appear. Conversely, full-time employees may seek to reduce their hours when young children are in the home, as the number of dependents declines, as elder care responsibilities appear, or as the employee ages.

Marital or partner status may also play a role in generating a divergence between usual and preferred work hours. Single or lone parents may be so income-constrained that longer (though not full-time) hours are typically preferred, as was found in a study of the first wave of the HILDA data (Drago, Tseng and Wooden 2004). For employees who are partnered, high household net worth may make reduced hours employment more feasible. Relatedly, the work hours of partners may also alter preferred work hours; the neotraditional family reflects in part the fact that financial rewards may be very high for one member of the couple working extremely long hours, with the other picking up most of the resulting shortfall of unpaid work in the home in tandem with reduced hours employment.

The tests provided below therefore begin with the notion that some part-time (full-time) employees are driven to select into the status of desiring more (fewer) hours, and may then encounter systematic resistance to the shift in the form of drop ceilings (trap-door floors).

\section{Data and Methods}

As noted previously, the data used in this analysis come from the first two waves of the Household, Income and Labour Dynamics in Australia (or HILDA) Survey. ${ }^{6}$ Described in more detail in Watson and Wooden (2002), the HILDA Survey is a longitudinal household panel survey. Funded by the Australian Government, it began, in 2001, with a large national probability sample of households, and involved personal interviews with all household members aged 15 years and over. In wave one, interviews were obtained at 7682 households, which represented 66 per cent of all households identified as in-scope. This, in turn, generated a sample of 15,127 persons eligible for interview, 13,969 of whom were successfully interviewed. In 2002 all responding households from wave one were re-contacted. ${ }^{7}$ Interviews were again sought with all household members aged 15 years or over, including persons who did not respond in wave one, as well as any new household members. In total, interviews were

\footnotetext{
${ }^{6}$ More specifically, the data used are from the HILDA Survey confidentialized unit-record file, Wave 1 - Wave 2, release 2.0, issued on CD-Rom in January 2004.

${ }^{7}$ The actual interview period runs from late August to the following March each year.
} 
completed with 13,041 persons from 7245 households. Of this group, almost 12,000 were respondents from wave one, which represented almost 87 per cent of the wave one individual sample. A third wave was conducted in 2003. At the time of writing, however, data were only publicly available from the first two waves.

While the coverage of the HILDA Survey is extremely broad, it is intended to have a focus on household structure and formation, income and economic well-being, and employment and labour force participation. For this analysis the most important feature of the survey is its collection of data on employment status and usual weekly hours of work and, most critically, preferred weekly hours of work, at each wave. That is, all employed respondents are first asked how many hours per week they usually work in all their jobs (including any paid or unpaid overtime) and second, how many hours per week they would prefer to work if they were free to choose. Of course, if work is inferior to leisure it might be expected that many might answer zero to this. Respondents were thus explicitly asked to take into account the effect of a change in hours of work on income. ${ }^{8}$

The analysis reported on in this paper is conducted on two separate sub-samples, both of which exclude any cases not responding in wave two. One sub-sample involves all respondents employed or self-employed part-time during wave one, and comprises 1906 observations. This sub-sample is used to test for drop ceiling effects. The other sub-sample involves all respondents employed or self-employed full-time during wave one, and involves 4681 observations.

For the part-time sub-sample, the initial dependent variable is WM for "Want More," a dummy variable that is unity if the employee wishes to work at least five more hours per week during wave one, and zero otherwise. Conditional on preferring longer hours, the final dependent variable is GM for "Get More," a dummy variable capturing those employees whose reported weekly hours rise by at least five between the two survey waves.

By parallel construction, for the full-time sub-sample, the initial dependent variable is WL for "Want Less," a dummy variable taking the value of unity if the employee wishes to work at least five hours less during wave one, and taking a value of zero otherwise. For those

\footnotetext{
${ }^{8}$ Preferred hours of work was derived from two questions. Respondents were first asked: "If you could choose the numbers of hours you work each week, and taking into account how that would affect your income, would you prefer to work ... fewer hours than you do now? about the same as you do now? or more hours than you do know? Those who indicated a preference for more or less were then asked the following: "In total, how many hours per week, on average, would you choose to work? Again, take into account how that would affect your income?" The questionnaire also included an interviewer prompt which read as follows: "If respondent indicates that they would prefer not to work at all, emphasize that this also means that they will receive no income from wages or salary."
} 
employees hoping to scale back, the final dependent variable is GL for "Get Less," a dummy variable that is unity if reported hours fall by at least five between survey waves.

For part-time employees in wave one, the drop ceiling model can be cast as involving estimates of:

$$
\begin{aligned}
& \operatorname{Pr}(W M)=\mathrm{AX}+\varepsilon, \text { and } \\
& \operatorname{Pr}(G M \mid W M)=\mathrm{a} \lambda+\mathrm{BY}+\mu .
\end{aligned}
$$

where $\mathrm{A}$ and $\mathrm{B}$ are vectors of coefficients, $\mathrm{X}$ and $\mathrm{Y}$ are vectors of independent variables, and $\varepsilon$ and $\mu$ are error terms. Equation (1) estimates the probability of wanting more hours (WM) as a function of a set of independent variables and an error term, while (2) estimates the probability of getting more hours (GM), conditional on wanting more (WM), and as a function of a set of independent variables and an error term. Because both equations concern probabilities, a probit regression method is applied to each. Following standard sample selection procedures (Heckman 1979), $\lambda$ is estimated from (1) and is used as an independent variable to correct for sample selection in the estimation of (2). Note, however, that if sample selection effects are insignificant (according to the coefficient 'a'), then (1) and (2) should be estimated separately.

The trap-door floor hypothesis can be tested for the sub-sample of full-time employees through estimation of:

$$
\begin{aligned}
& \operatorname{Pr}(W L)=\mathrm{AX}+\varepsilon, \\
& \operatorname{Pr}(G L \mid W L)=\mathrm{a} \lambda+\mathrm{BY}+\mu,
\end{aligned}
$$

again using probit regression and the sample selection correction if warranted.

The key independent variable for testing Hypothesis 1, as shown in Table 1, is a gender dummy that takes a value of unity for women and zero for men. The drop ceiling and trap-door floor hypotheses will receive support if the coefficients on the gender variables are negative and significant in estimates of equations (2) and (4), respectively. 
TABLE 1

MEANS AND STANDARD ERRORS OF INDEPENDENT VARIABLES

\begin{tabular}{|c|c|c|c|c|}
\hline \multirow[t]{2}{*}{ Variable } & \multicolumn{2}{|c|}{ PT sub-sample } & \multicolumn{2}{|c|}{ FT sub-sample } \\
\hline & Mean & Std. error & Mean & Std. error \\
\hline \% Women (WM) & 0.716 & 0.012 & 0.328 & 0.008 \\
\hline \% Professional/Managerial Occup. & 0.214 & 0.010 & 0.351 & 0.008 \\
\hline WM x \% Prof./Managerial Occup. & 0.164 & 0.009 & 0.127 & 0.005 \\
\hline WM Partnered / No Children & 0.362 & 0.012 & 0.015 & 0.002 \\
\hline MN Partnered / No Children & 0.091 & 0.008 & 0.370 & 0.008 \\
\hline WM Partnered / Children 0-4 & 0.105 & 0.007 & 0.016 & 0.002 \\
\hline WM Single / Children 0-4 & 0.011 & 0.003 & 0.002 & 0.0006 \\
\hline MN Partnered / Children 0-4 & 0.018 & 0.003 & 0.112 & 0.005 \\
\hline MN Single / Children 0-4 & 0.001 & 0.001 & 0.0004 & 0.0003 \\
\hline WM Elder / Partner Care & 0.041 & 0.005 & 0.015 & 0.002 \\
\hline MN Elder / Partner Care & 0.017 & 0.004 & 0.018 & 0.002 \\
\hline Age & 35.712 & 0.347 & 38.45 & 0.188 \\
\hline Age squared & 1455.7 & 25.72 & 1604.9 & 14.546 \\
\hline Casual Employees & 0.506 & 0.013 & 0.092 & 0.005 \\
\hline Self-Employed & 0.161 & 0.009 & 0.183 & 0.006 \\
\hline Union Members & 0.212 & 0.011 & 0.305 & 0.007 \\
\hline Public Sector & 0.180 & 0.009 & 0.212 & 0.006 \\
\hline Non-profit Sector & 0.048 & 0.006 & 0.028 & 0.003 \\
\hline Workplace $20+$ employees & 0.454 & 0.013 & 0.542 & 0.008 \\
\hline Organisation $100+$ employees & 0.445 & 0.013 & 0.521 & 0.008 \\
\hline Change Employers W1 to W2 & 0.232 & 0.001 & 0.151 & 0.006 \\
\hline Partner's Usual Work Hours & 21.270 & 0.649 & 20.001 & 0.365 \\
\hline Net Worth $(\$)$ & 478,510 & 1469 & 445,353 & 8531.7 \\
\hline Satisfaction with Leisure Time & 6.589 & 0.072 & 5.724 & 0.042 \\
\hline Sample size & \multicolumn{2}{|c|}{1906} & \multicolumn{2}{|c|}{4681} \\
\hline
\end{tabular}

NOTE: All variables drawn from Wave one data, except Net Worth, which uses data from Wave two, and Change Employers, which is constructed from data from both waves.

Hypothesis 2 suggests the inclusion of a variable identifying employment in a managerial or professional occupation. ${ }^{9}$ The variable should attract a negative coefficient in equations (2) and (4). The interaction with gender will attract a negative coefficient in the equations if Hypothesis 2a holds.

\footnotetext{
${ }^{9}$ Respondents are classified into occupations using the Australian Standard Classification of Occupations. We combined the two one-digit groups: Managers and administrators and Professionals to create the variable.
} 
Hypothesis 3, concerning women changing employers more often than men to achieve desired hours, needs to be tested in a different way. Specifically, we need to ascertain whether part-time employed women seeking to increase their hours switch employers to do so more often than men in the same situation. Similarly, we need to find out whether full-time employed women preferring reduced hours change employers more often than similarly situated men. A test for differences of proportions can be directly applied to the data to answer this question. Regardless, a control for employment change is used in estimating (2) and (4) to avoid attributing hours changes to the original employer that were in fact related to a different employer. Note that the employment change variable is the only independent variable that uses information from wave two of the survey (along with net worth, discussed below). Since it does so, however, it cannot be used as a control in (1) and (3), where the dependent variables are from wave one (this is not the case in (2) and (4)).

Hypothesis 4 concerns caregiving, while Hypothesis $4 \mathrm{a}$ addresses gender effects around caregiving. To analyze caregiving commitments requires the use of several variables. To get at the intersecting issues of gender, marital or partner status, and children, we created several mutually exclusive categories, implicitly leaving single men with no children as the omitted category. ${ }^{10}$ As shown in Table 1, the categories are then for women who are partnered with no children under the age of five, for comparable men, for partnered women with young children, single women with young children, partnered men with young children, and single men with young children. Because the latter group is so small, they disappear from estimates of equations (2) and (4). In addition, we created separate dummy variables for women and for men who report usually providing at least four hours of care for an elder or disabled adult relative each week.

We initially test Hypothesis 1 using the raw (though weighted) figures and then estimate equations (2) and (4) using just the gender dummy while controlling for sample selection if relevant. We then add the professional/managerial occupation dummy and its interaction with gender to test Hypotheses 2 and 2a, along with the carework variables to test Hypotheses 4 and 4a. We finally add in all control variables, including an age quadratic, a dummy for casual

\footnotetext{
${ }^{10}$ Single, childless men and women would be the reference group excepting the fact that we include the gender dummy in the regressions.
} 
employment (for part-timers only), ${ }^{11}$ and dummy variables for self-employment, union membership, public sector employment, non-profit sector employment, large workplaces (more than 20 employees), large firms (more than 100 employees) and a variable for job change.

Identification of the sample selection system requires that at least one variable be included in the first-stage regressions, (1) and (3), that is not in the second stage. This involves finding some variable likely to affect the divergence between preferred and usual hours, but not whether desired hours are achieved. Variables related to the family, but largely unknown to the employer would be good candidates here, and three variables are deployed for this purpose. The first is partner's usual hours of work. Presumably, having a partner who works very long hours will reduce desired hours for the respondent and, conversely, having a partner who works short hours is likely to increase preferred hours (and income) for the respondent. Second, net worth (assets less debts) of the family may alter desired hours, since greater wealth will reduce the need for wage income. ${ }^{12}$ Third, satisfaction with leisure time may be related to desired hours such that individuals who believe they have little leisure time would seek shorter hours of work. ${ }^{13}$ In each case, it is not obvious that the employer would have relevant information, and so alter the employee's ability to shift hours as a result.

All reported results have been weighted by the longitudinal personal weight included in the HILDA data set. This weighting allows for estimates of population figures in part by correcting for attrition bias during the two waves of data collection. We also perform specification tests in terms of switching the desired and actual hours change cut-off from five to either seven or three hours, by moving the age cut-off for dependent children from age four to age 14 , and by adding eight occupation and up to 17 industry dummy variables to the equations. $^{14}$

\footnotetext{
${ }^{11}$ Casual employees are frequently defined as those employees who do not have paid leave entitlements. We instead use self-definition, with the respondent given the choice as to whether to define him or herself as a casual employee. See Wooden and Warren (2004) for further discussion.

${ }^{12}$ The HILDA net worth variable is computed from a series of detailed questions, asked at the household and individual level in wave two, concerning various assets and debts, with assets valued at resale levels, and only excluding household furnishings. Note that the variable is only available for wave two of the HILDA, so we implicitly assume net worth is reasonably constant such that it can be treated as a wave one variable in equations (1) and (3).

${ }^{13}$ This question was asked within a battery of satisfaction questions, scored from 0 to 10 , and specifically asked how satisfied respondents were with "the amount of free time you have."

${ }^{14}$ The Australian and New Zealand Standard Industrial Classification provides 17 industry categories at the simplest level, so we constructed 16 industry dummies variables, using Retail trade as the reference group, and added an additional dummy variable for missing data on industry.
} 


\section{Results}

Table 2 presents weighted population estimates relevant to Hypothesis 1. Less than 15 percent of employed men, but almost half of employed women, were working part-time in late 2001. Of those employed part-time, 40 percent of the men and just over 26 percent of the women expressed a preference for at least five more hours of work during wave one. Out of those groups, over 57 percent of the men, but less than 42 percent of the women, had increased their work hours by at least five by wave two. These raw figures suggest that the labor market is functioning effectively for many individuals - even in the worst case, over two-fifths of women desiring an increase achieved that result a year later. Nonetheless, the figures are also consistent with a gendered drop ceiling: using a chi-squared test for differences of proportions, we find part-time employed women are significantly less likely $(\mathrm{p}<.001)$ to be able to increase their work hours, supporting Hypothesis 1.

Regarding trap-door floors, around one-third of full-time employed men desired at least five fewer hours in wave one, while over 40 percent of full-time employed women did. Of those employed full-time and desiring fewer hours, over one-third of men and women were able to reduce their work hours by at least five by wave two. Here there is no evidence supporting Hypothesis 1, since the figures for men and women are virtually identical. Nonetheless, in comparing these figures to those for the drop ceiling, it appears that the trap-door floor effect is stronger. Indeed, the percentage of both part-time men and part-time women able to increase their hours as desired is significantly higher than the percentage of either full-time men or women able to reduce their hours as desired. ${ }^{15}$

\footnotetext{
${ }^{15}$ This claim involves four comparisons, that full-time men desiring shorter hours are significantly less likely to achieve the result than part-time men desiring longer hours $(\mathrm{p}<.000)$, and similarly for women full-time compared to men part-time $(\mathrm{p}<.000)$, for women full-time compared to women part-time $(\mathrm{p}<.023)$, and for men full-time compared to women part-time $(\mathrm{p}<.055)$.
} 
TABLE 2

Weighted Percentages of Men and Women in Usual and Desired Work Hours CATEGORIES

\begin{tabular}{lcc}
\hline \hline & Men & Women \\
\hline $\begin{array}{l}\text { Part-time (PT) employed Wave1 (W1) } \\
\text { Full-time (FT) employed W1 }\end{array}$ & 14.66 & 47.03 \\
$\begin{array}{l}\text { \% of PT employed W1 that wanted 5+ more hours } \\
\begin{array}{l}\text { \% of PT employed that wanted 5+ more hours W1 } \\
\text { that got 5+ more hours by W2 }\end{array}\end{array}$ & 40.00 & 52.97 \\
$\begin{array}{l}\text { \% of FT employed W1 that wanted 5+ less hours } \\
\begin{array}{l}\text { \% of FT employed that wanted 5+ less hours W1 } \\
\text { that then got 5+ less hours in W2 }\end{array}\end{array}$ & 37.63 & 41.82 \\
\hline
\end{tabular}

Estimates of equation (1) for whether part-time employees desire at least five more hours per week, and of equation (3) for whether full-time employees desire at least five fewer hours, are reported in Table 3. Although these equations are not used for hypothesis testing, the results warrant some discussion. We find that part-time employed women and professionals are significantly less likely to want more hours, while professionals employed full-time are significantly more likely to desire reduced hours. The latter result is primarily confined to men, since the gender interaction term runs in the opposite direction and is significant. For the carework variables, we find that full-time employed partnered women with young children are significantly more likely to desire reduced hours, consistent with life course considerations. Single men with children who are part-time employed tend to desire longer hours, and their fulltime counterparts tend not to desire shorter hours, presumably because income needs drive them to desire longer hours of employment. Perhaps surprisingly, full-time employed women performing care for an elderly family member or disabled partner are significantly less likely to report a preference for shorter hours, a result that might be attributable to a heightened need for income in such circumstances, particularly where care is being provided to a disabled partner. Age effects are also significant, and suggest that among part-timers, the strongest estimated 
TABLE 3

Estimates of Want More (WM) Hours For Part-Timers (1) AND WANT Less (WL) Hours FOR FULL-TIMERS (3): PROBIT RESULTS

\begin{tabular}{|c|c|c|c|c|}
\hline & \multicolumn{2}{|c|}{$\begin{array}{l}\text { Want More } \\
\text { PT subsample }\end{array}$} & \multicolumn{2}{|c|}{$\begin{array}{c}\text { Want Less } \\
\text { FT subsample }\end{array}$} \\
\hline & Coefficient & $\mathrm{SE}$ & Coefficient & SE \\
\hline \% Women (WM) & -.262 & $.118^{* *}$ & .155 & .099 \\
\hline$\%$ Professional/Managerial Occup. & -.633 & $.196 * * *$ & .353 & $.060 * * *$ \\
\hline WM x \% Professional/Managerial Occup. & .400 & $.218^{*}$ & -.208 & $.102 * *$ \\
\hline WM Partnered / No Children & -.110 & .182 & -.003 & .121 \\
\hline MN Partnered / No Children & .044 & .194 & -.142 & .089 \\
\hline WM Partnered / Children 0-4 & -.244 & .203 & .364 & $.194 *$ \\
\hline WM Single / Children 0-4 & -.045 & .362 & -.365 & .927 \\
\hline MN Partnered / Children 0-4 & .005 & .273 & -.143 & .091 \\
\hline MN Single / Children 0-4 & 5.952 & $.222 * * *$ & -6.409 & $.734 * * *$ \\
\hline WM Elder / Partner Care & -.093 & .181 & -.374 & $.197^{*}$ \\
\hline MN Elder / Partner Care & .512 & $.288 *$ & -.055 & .163 \\
\hline Age & .085 & $.022 * * *$ & .067 & $.016 * * *$ \\
\hline Age squared $(/ 100)$ & -.119 & $.029 * * *$ & -.069 & $.020 * * *$ \\
\hline Casual Employee & .364 & $.094 * * *$ & & \\
\hline Self-employed & .206 & .138 & -.040 & .075 \\
\hline Union Member & -.030 & .100 & .068 & .055 \\
\hline Public Sector & -.023 & .110 & -.124 & $.064 *$ \\
\hline Non-profit Sector & -.053 & .178 & .142 & .128 \\
\hline Workplace $20+$ employees & .008 & .094 & -.022 & .062 \\
\hline Organization $100+$ employees & .070 & .099 & -.055 & .064 \\
\hline Partner's Usual Work Hours & -.006 & $.003 *$ & .004 & $.002 * *$ \\
\hline Net Worth & $-.002+$ & $.0008 * * *$ & $.002+$ & $.0005 * * *$ \\
\hline Satisfaction with Leisure Time & .046 & $.015 * * *$ & -.147 & $.010 * * *$ \\
\hline Constant & -1.887 & $.404 * * *$ & -1.245 & .314 \\
\hline Pseudo R-squared & \multicolumn{2}{|c|}{.088} & \multicolumn{2}{|c|}{.107} \\
\hline Chi-squared statistic & \multicolumn{2}{|c|}{$132.43 * * *$} & \multicolumn{2}{|c|}{$425.12 * * *$} \\
\hline Sample size & \multicolumn{2}{|c|}{1654} & \multicolumn{2}{|c|}{4117} \\
\hline
\end{tabular}

NOTES: Survey weights are applied, and robust standard errors are reported.

+ coefficient and standard error multiplied by 10,000 due to small absolute size.

$*, * *, * *$ Denote statistical significance at the 0.10 level, 0.05 level, 0.01 level.

desire for increased hours occurs at 42.5 years of age. In comparison, for full-timers the strongest estimated desire to reduce hours occurs at 47.9 years of age. Both of these results are intuitive in terms of income needs and the aging of children, although the estimate does not pick up any desire among full-time employees to slow down as retirement nears. Part-time casual 
employees are more likely to desire increased hours, a result that is probably due to casuals working the shortest average hours among part-timers. ${ }^{16}$ In addition, full-time public sector employees are slightly less likely to desire reduced hours, while the variables used to identify the sample selection system perform reasonably, with long partner hours of work associated with a heightened desire among full-timers for reduced hours and a slightly lessened desire for increased hours among part-timers, a greater family net worth associated with preferences for reduced hours, and satisfaction with leisure time associated with a stronger desire for longer hours among part-timers and a lesser desire to reduce hours among full-timers.

Turning to regression tests for drop ceiling effects, Table 4 reports simple probit estimates of equation (2). Note that the coefficient on $\lambda$ was uniformly insignificant in the sample selection regressions, so is not included in estimates of (2). The initial regression, including just the gender dummy and a constant, finds a significant negative gender effect, consistent with Hypothesis 1. Furthermore, even after the inclusion of variables to test Hypotheses 2, 2a, 4 and 4a in the second regression, the gender coefficient remains significant. However, in that same regression none of the other coefficients for testing Hypotheses 2, 2a, 4 or 4a achieve significance except for the coefficient for single mothers, which is positively signed and of borderline significance. Contrary to predictions, here we find caregiving associated with an enhanced probability of achieving longer hours when so desired. Perhaps employers believe that single mothers are more dedicated than others due to their serving as the sole breadwinner in the family.

Once the additional control variables are included in the third and final regression, the gender coefficient continues to remain significant and negative, and the coefficient for single mothers remains positive and weakly significant. Age, casual employment, union membership, public or non-profit sector employment, and large organization size exert no significant effects. However, self-employment has a positive and significant effect, consistent with organizations imposing drop ceilings; workplaces with more than 20 employees facilitate hours increases, consistent with greater substitutability among employees in larger workplaces; and job change is positively and significantly associated with achieving desired hours increases, as expected. We

\footnotetext{
${ }^{16}$ Among part-time employees in our sample, the correlation between usual work hours and casual employment status is $-.318(\mathrm{p}<.01)$.
} 
label these final results as the 'preferred regression' and use them for specification tests reported below.

TABLE 4

Estimates of Get More (GM) Hours for Part-Timers Who Desire It (2): Probit Results

\begin{tabular}{|c|c|c|c|}
\hline & Coefficient (S.E.) & Coefficient (S.E.) & Coefficient (S.E.) \\
\hline \% Women (WM) & $-.398(.126) * * *$ & $-.503(.179) * * *$ & $-.331(.188)^{*}$ \\
\hline \% Professional/Managerial Occup. & & $-.037(.344)$ & $-.020(.336)$ \\
\hline WM x \% Prof./Managerial Occup. & & $-.227(.395)$ & $-.196(.389)$ \\
\hline WM Partnered / No Children & & $.040(.162)$ & $.185(.174)$ \\
\hline MN Partnered / No Children & & $-.230(.240)$ & $.000(.262)$ \\
\hline WM Partnered / Children 0-4 & & $-.044(.228)$ & $-.129(.252)$ \\
\hline WM Single / Children 0-4 & & $1.188(.645)^{*}$ & $1.210(.661)^{*}$ \\
\hline MN Partnered / Children 0-4 & & $-.025(.404)$ & $-.058(.363)$ \\
\hline WM Elder / Partner Care & & $-.503(.329)$ & $-.498(.343)$ \\
\hline MN Elder / Partner Care & & $-.200(.356)$ & $-.191(.377)$ \\
\hline Age & & & $.043(.033)$ \\
\hline Age squared $(/ 100)$ & & & $-.069(.045)$ \\
\hline Casual Employee & & & $.146(.165)$ \\
\hline Self-employed & & & $.538(.237)^{* *}$ \\
\hline Union Member & & & $-.177(.177)$ \\
\hline Public Sector & & & $.039(.185)$ \\
\hline Non-profit Sector & & & $-.456(.346)$ \\
\hline Workplace $20+$ employees & & & $.393(.154)^{* *}$ \\
\hline Organization $100+$ employees & & & $-.176(.157)$ \\
\hline Change Employers W1 to W2 & & & $.539(.147)^{* * *}$ \\
\hline Constant & $.383(.101)^{* * *}$ & $.466(.135)^{* * *}$ & $-.635(.561)$ \\
\hline Chi-squared statistic & $10.00 * * *$ & $21.69 * * *$ & $60.48 * * *$ \\
\hline Pseudo R-squared & .017 & .036 & .095 \\
\hline Sample size & 566 & 521 & 521 \\
\hline
\end{tabular}

NOTES; Survey weights are applied, and robust standard errors are reported.

$*, * *, * * *$ Denote statistical significance at the 0.10 level, 0.05 level, 0.01 level.

Table 5 reports regression results relevant to the trap-door floor hypothesis. Sample selection effects are significant in the full specification, so are reported across all regressions. Although the gender coefficient does not achieve significance when gender alone is entered, the negative predicted effect for Hypothesis 1 is found and of borderline significance once the 
variables for testing Hypotheses 2, 2a, 4 and 4a are included, although significance declines again once all of the control variables are included. ${ }^{17}$

Regarding Hypothesis 2, the coefficient for professional/managerial occupation in the second regression is significant and negative as predicted. However, Hypothesis 2a receives no support, since the gender interaction term is insignificant.

TABLE 5

Estimates of Get Less (GL) Hours for Full-Timers Who Desire It (4): Probit Results

\begin{tabular}{lccc}
\hline \hline & Coefficient (S.E.) & Coefficient (S.E.) & Coefficient (S.E.) \\
\hline \% Women (WM) & $-.098(.081)$ & $-.291(.168)^{*}$ & $-.190(.163)$ \\
\% Professional/Managerial Occup. & $-.195(.097)^{* *}$ & $-.169(.098)^{*}$ \\
WM x Prof./Managerial Occup. & $.149(.155)$ & $.188(.151)$ \\
WM Partnered / No Children & & $.239(.148)$ & $.288(.142)^{* *}$ \\
MN Partnered / No Children & & $.015(.124)$ & $.160(.123)$ \\
WM Partnered / Children 0-4 & & $.149(.245)$ & $.148(.244)$ \\
MN Partnered / Children 0-4 & & $.068(.149)$ & $.235(.145)$ \\
WM Elder / Partner Care & $-.862(.332)^{* * *}$ & $-.764(.333)^{* *}$ \\
MN Elder / Partner Care & $-.459(.288)$ & $-.375(.277)$ \\
Age & & & $-.120(.027)^{* * *}$ \\
Age squared (/100) & & $.142(.032)^{* * *}$ \\
Self-employed & & & $.323(.110)^{* * *}$ \\
Union Member & & & $-.031(.084)$ \\
Public Sector & & & $-.202(.106)^{*}$ \\
Non-profit Sector & & & $-.055(.187)$ \\
Workplace 20+ employees & & $.152(.100)$ \\
Organization 100+ employees & & & $-.042(.100)$ \\
Change Employers W1 to W2 & & & $.469(.102)^{* * *}$ \\
Constant & & & $2.228(.580)^{* * *}$ \\
$\Lambda$ & $-.111(.158)$ & $-.000(.228)$ & $-.400(.160)^{* *}$ \\
Chi-squared statistic & $-.244(.173)$ & $91.97 * * *$ \\
Sample size & & & 4117 \\
\hline
\end{tabular}

NOTES; Survey weights are applied, and robust standard errors are reported.

$*, * *, * * *$ Denote statistical significance at the 0.10 level, 0.05 level, 0.01 level.

For Hypothesis 4, in the second regression, we find women with care responsibilities for an elder or disabled partner significantly less likely to be able to achieve desired hours reductions, consistent with both Hypothesis 4 and its gendered variant in $4 \mathrm{a}$. Once all of the

\footnotetext{
${ }^{17}$ Note that the variable for single mothers of young children was omitted from the regressions because only one such person existed in the relevant sub-sample.
} 
controls are introduced in the third regression, we also find that partnered women with no young children are significantly more likely to receive reduced hours when desired, consistent with the possibility that their caregiving commitments are minimal. In general, however, few of the carework coefficients attract significance, consistent with the possibility that employers may often be unaware of caregiving responsibilities due to bias avoidance behaviors among employees.

Continuing with the third ('preferred') regression and the control variables, we discover a curvilinear age effect, with the ability to gain reduced hours declining, and then rising. The estimated minimum occurs at 43.2 years of age, suggesting that employers only make reduced hours options available to young employees and to those approaching retirement age. Stated differently, estimated age effects suggest that employers hold employees more closely to the ideal worker norm via trap-door floors during the prime earning years, as we suspected. We also find self-employment significantly improving the opportunities to reduce work hours, consistent with the notion that organizations tend to introduce trap-door floors, that public sector employment limits opportunities to reduce hours (though the association is only weakly significant), and that changing employers provides a route to achieving desired hours reductions. The public sector employment result could be due to many of the relevant full-time employees working fewer hours (i.e. closer to 40 per week) than the average private sector employee, and reducing hours from, say, 40 to 35 hours per week might be more difficult than achieving a reduction from 60 to 55 hours. ${ }^{18}$

Simulations were undertaken using the predicted probabilities from the preferred specifications reported in Tables 4 and 5. ${ }^{19}$ For part-time employees seeking longer hours, women have a 13.0 percent lesser probability of achieving the desired result, the self-employed enjoy a 20.2 percent increase in the probability of attaining increased hours when desired, employees in workplaces with more than 20 employees experience an estimated 15.4 percent increased probability, while job change raises the probability by 20.8 percent. For full-time employees seeking reduced hours, professionals and managers face a 6.5 percent lower probability of attaining that outcome, women who perform care for an elder or disabled partner confront a 24.0 percent reduction in the probability, the self-employed enjoy a 13.0 percent

\footnotetext{
${ }^{18}$ Consistent with this possibility, the correlation between public sector employment and usual working hours among the full-time employed is -.156 .

${ }^{19}$ These simulations use the average of the predicted probabilities for each individual in the sample.
} 
advantage in the ability to reduce hours, public sector employees experience an estimated 7.8 percent disadvantage, and job change increases the chance of obtaining reduced hours by 19.1 percent.

Specification tests began with the re-running of the preferred specifications from Tables 4 and 5 after changing the desired and actual hours shift cut-points to three hours and then to seven hours to ascertain whether the five hour cut-off used in the analysis is reasonable. For the three hour cut-off, the general pattern of results remained unchanged for the Get More regression (Table 4), excepting that the gender coefficient drops to borderline significance, the negative coefficient for women performing elder or partner care rises in absolute value to achieve significance at the 10 percent level, and the large organization size coefficient rises from -.176 in Table 4 to -.448 , and significance at the 1 percent level. Changing the hours cut-off to seven again reveals a common pattern of results, except gender loses significance, the elder and partner care coefficient for women remains negative but achieves significance, and the interaction between gender and professional/managerial employment remains negative but achieves significance at the 10 percent level.

For the Get Less regression for full-time employees, switching the hours cut-off to three results in minor changes in significance, with very similar coefficients, except the coefficient for single mothers achieves significance at the 1 percent level, and that for large organizations remains negative but achieves significance at the 10 percent level. Results after raising the hours cut-off to seven mirror closely those reported in Table 5.

We next checked the effect of raising the dependent child age cut-off from four to 14 years for the carework variables. For the Get More regression, the pattern of results remained unchanged but with some declines in significance levels. For the Get Less regression, however, while most coefficients retained size and significance as before, the coefficients for partnered women with children remained positive but achieved significance at the five percent level. These results suggest that as children age and enter school, parents find it easier to reduce their work hours, perhaps because the costs of and time constraints around child care ease at that point.

The third set of specification tests involved the addition of eight occupational and up to seventeen industry dummy variables to the equations. Although the addition of the variables significantly improved the fit of each equation, the basic pattern of results in both the Get More 
and Get Less equations remained. ${ }^{20}$ Additional findings for the part-time subsample in the Get More equation included a significant positive effect from employment in the Wholesale trade, Transport and storage, and Personal and other services industries, relative to the reference category of Retail trade. For the full-time subsample in the Get Less regression, we found that, relative to Professionals, Tradespersons, Intermediate clerical, sales and service workers, and Laborers and related workers were significantly more likely to achieve desired hours reductions, as were employees in the Communication services and Health and community services industries, relative to those in Retail trade.

In sum, the specification tests suggest that the results reported here are reasonably robust. However, we may have underestimated the negative effects of working for large organizations, where both drop ceilings and trap-door floor effects may be stronger. Also, the significant effects of even crude controls for occupation and industry suggest that institutional context is important for understanding these phenomena.

To test Hypothesis 3 requires comparing the proportions of women and men who desired more or fewer hours in wave one, and changed employers by wave two. We predicted that a higher proportion of women will need to and in fact change employers to achieve desired hours. Of the sub-sample of those part-time employed in wave one and desiring at least five more hours per week, 21.6 percent of the women, but 48.6 percent of the men, changed employers, contrary to our prediction. For those full-time employed in wave one and desiring at least five fewer hours per week, 16 percent of the women and 16.7 percent of the men changed employers, again providing no support for Hypothesis 3. An examination of job change figures for those who did not desire a change in hours suggests that men are more likely to change employers to achieve their desired hours, while women tend to switch employers less frequently and for other reasons. $^{21}$ We can speculate that women face greater constraints in terms of job mobility, perhaps due to marriage. Regardless of that possibility, the results do not support Hypothesis 3.

A group not discussed to this point includes respondents employed in wave one who were no longer employed in wave two. In analyses provided in Appendix Tables 2 and 3, we find that

\footnotetext{
${ }^{20}$ The pseudo R-squared statistic for the Get More equation rose to .127 , while the chi-squared statistic for the Get Less equation rose to 136.65 .

${ }^{21}$ Of the part-time men who did not desire more hours, only 27.5 percent changed employers compared to 48.6 percent of those who desired more hours making a switch. Of part-time women who did not desire more hours, 16.5 percent changed employers compared to 21.6 percent of those who desired more hours. Of full-time men who did not (did) desire fewer hours, 13.3 percent (16.7 percent) changed jobs, and of full-time women who did not (did) desire fewer hours, 16.8 percent (16 percent) changed employers.
} 
compared to part-time employed men who were satisfied with their hours, part-time employed men who desired more hours in wave one were only two-thirds as likely to move into either unemployment or out of the labor force by wave two, a difference that is significant $(\mathrm{p}<.072)$ for movement out of the labor force. For part-time employed women in wave one, however, those who desired more hours were more than twice as likely to enter unemployment by wave two, a difference that is also significant $(\mathrm{p}<.014)$. Since we know from earlier estimates that part-time employed women face stronger drop ceilings than men, this difference may represent recognition among part-time employed women that attempts to increase hours will likely fail, hence leading them to give up and search for employment elsewhere. Alternatively, women may have greater financial resources from a partner to sustain a bout of unemployment while searching for a new job.

Among the full-time employed, dissatisfaction with work hours among men was not linked to movement out of the labor force. For full-time employed women, those who desired fewer hours were less likely to move into unemployment, but more likely to move out of the labor force, though neither difference achieves statistical significance due to the relatively small numbers involved. The latter results suggest that women sometimes respond to trap-door floors by quitting the labor force entirely as a way to reduce work hours.

From the results presented thus far, we do not actually know whether there is any "drop" in the drop ceilings: were women working part-time previously full-time? With only two waves of data, we cannot test for this behavior directly. Nonetheless, the ABS figures mentioned earlier suggest that 55.3 percent of employed mothers in Australia work part-time. Looking at the HILDA data, we identified 49 women who were employed and childless in wave one, and bore a child by wave two. Of those women, only six, or 12.2 percent of the total, were employed parttime at the time of the wave one survey administration, with the remainder employed full-time. Though the sample size is small, it nonetheless suggests that most employed mothers were working full-time prior to the arrival of children, so there is indeed typically a "drop" in drop ceilings.

Finally, we tested the preferred specifications for Get More and Get Less for any interactive effects of gender with public sector employment and with self-employment. We were led to consider the prior interaction given the negative (though weakly significant) effect of government employment on the ability of full-time employees to reduce their hours when 
desired. Those interaction terms were, however, insignificant. We also considered the possibility of gender effects for self-employment because of the literature suggesting that selfemployment offers mothers a device for balancing work and family, hence altering hours as desired. Among full-time employees wishing to reduce their hours, the coefficient for gender interacted with self-employment was insignificant. However, for part-time employees desiring increased hours, the interaction coefficient was highly significant and negative, implying that the ability of part-timers to increase their hours through self-employment is mainly confined to men. ${ }^{22}$ The argument that self-employment provides particular advantages to mothers receives no support here.

\section{Discussion}

Looking over the broad pattern of results presented here, it seems safe to conclude that drop ceilings and trap-door floors are often encountered by Australian employees. Part-time employees often face drop ceilings such that it is difficult for them to increase their working time; these employees are often branded as no longer fitting the ideal worker mold and locked out of longer hours jobs. Full-time employees often confront trap-door floors in the form of choices between continuing full-time or quitting the organization; these employees are limited to either functioning as ideal workers or exiting the organization. The enhanced ability of the selfemployed to circumvent these constraints supports our claim that these phenomena exist, as does the improved ability of those who change employers to achieve desired increases or reductions in working time. Further, given the theory underlying these constructs was developed mainly in the U.S., it seems highly likely that the phenomena exist there as well.

In terms of our hypotheses, Hypothesis 1 received support for the drop ceiling: part-time employed women find it more difficult to increase their hours relative to comparable men. This result appeared in both the raw numbers and in a fully specified regression model. Hypothesis 1 did not receive support, however, with regard to trap-door floors. Full-time employed women found it no more difficult than men to reduce their work hours when so desired. Nonetheless, for men and for women, scaling back employment from full-time was significantly more difficult

\footnotetext{
${ }^{22}$ Specifically, from the third regression reported in Table 4, where the self-employment coefficient is .538 , after the gender interaction term is added, the self-employment coefficient proper rises to .925 , while the gender interaction coefficient is -.711 (s.d. .370), implying that self-employed men are far more likely to be able to increase their hours than self-employed women. Note also that the gender coefficient dropped from -.331, reported in Table 4, to -.270. While not a huge decline, note that significance was lost in the process.
} 
than increasing hours for part-time employees, suggesting that trap-door floor effects may in general be stronger than drop ceiling effects.

As mentioned earlier, we believe the opposite might be true in the U.S. That is, due to the relatively lower cost of part-time employees there, drop ceiling effects would probably appear more strongly in comparable U.S. data. Nonetheless, it might still be true that trap-door floors are more often imposed than drop ceilings: an employer who allows employees to work reduced hours might allow employees to vary their work hours over the life course or due to various events in their personal lives. By way of comparison, an employer with mainly or entirely full-time employees might hold a stronger bias against reduced hours employment for any reason.

Regarding Hypothesis 2 and the effects of professional/managerial employment, we found no evidence supporting drop ceiling effects. This finding is readily explicable from the preceding discussion: if an employer allows a manager or professional employee to work parttime, the ideal worker norm may be weak within the organization. For full-time employees desiring reduced hours, however, Hypothesis 2 was consistently supported, since it is significantly more difficult for professional and managerial employees to achieve desired reductions in hours relative to employees in other occupations. The gendered variant Hypothesis 2a, that these effects would be stronger for women in professional and managerial professions - received no support, suggesting there is gender equity in the application of the ideal worker norm to full-time professional and managerial employees.

Hypothesis 3 asserted that women would change jobs more frequently than men in order to evade drop ceilings and trap-door floors and achieve desired hours. In fact, men changed jobs more frequently in the sample, and in large measure for the purpose of altering their work hours. It is possible that the women are often constrained by family responsibilities - and particularly marriage - from changing employers.

Hypothesis 4 supposed that caregiving commitments would be associated with strong drop ceiling and trap-door floor effects, particularly for women (Hypothesis 4a). Results here were mixed, with the only variable linked to drop ceilings being a positive, though mild association between single motherhood and the ability for a part-time employee to increase their hours as desired. Among full-timers wishing to reduce their hours, we found the result more readily achieved for partnered women without children, and somewhat more easily achieved for 
fathers of young children. The finding that women with elder or partner care responsibilities face especially strong barriers to achieving reduced hours employment fits both Hypothesis 4 and its gendered variant in Hypothesis 4a. As mentioned earlier, the weakness of these findings is not surprising, since employees may engage in bias avoidance behaviors and hide caregiving commitments from their employer.

Among other findings, the hours preferences results were mainly reasonable, suggesting men employed part-time are more likely than women to desire longer hours, that full-time professionals and managers are more likely to desire reduced hours (or cast themselves as 'overworked'), that full-time employed women with partners and young children are likely to prefer reduced hours, and that age and various family circumstances alter hours preferences in predictable ways. Further, we discovered that the ability of full-time employers to achieve reductions in hours hits a minimum around the age of 43 . The latter result fits the notion that the ideal worker norm - and trap-door floor effects - is most heavily applied to employees in their prime earnings years. We also uncovered effects related to organizations, with workplaces employing more than 20 employees allowing desired hours changes more frequently, presumably because employees are more substitutable in these circumstances. Very differently, some evidence suggested that large organizations may be more likely to impose drop ceilings and trapdoor floors, consistent with the possibility that size is positively associated with the extent of bureaucracy, or perhaps it is the case that the ideal worker norm is stronger in large organizations.

Those who believe labor markets function reasonably well can take some comfort from our findings. Even in the worst case of men and women employed full-time who prefer reduced hours employment, over one-third of both groups had achieved the desired result a year later. By the same token, the results suggest that desires for reduced or increased hours expressed in crosssectional surveys should not simply be treated as expressions of wishful thinking, since many employees were found to have acted on those preferences over time.

The findings also suggest that labor markets function imperfectly, and that these imperfections are systematically linked to the norms of the ideal worker and of motherhood. Full-time professionals and managers who desire reduced hours, whether they are men or women, face stronger trap-door floor effects than employees in other occupations, consistent with the ideal worker norm being applied to this group such that opportunities for reduced hours 
employment are constrained. Women per se confronted stronger drop ceiling effects, facing more severe difficulties than men in achieving desired increases in working time among those employed part-time. The latter result is particularly troubling since it represents a previously undiscovered form of gender inequality in the labor market. Further, the ostensible advantages of self-employment for mothers in terms of achieving balance between work and family commitments turn out to be limited, since the ability of self-employed part-timers to increase their hours as desired was mainly limited to men, suggesting yet another source of gender inequality in the labor market.

For policy purposes, the existence of drop ceilings and trap-door floors suggests that labor market interventions may be warranted to allow employees to alter their hours over the life course. Specifically, Australia has made part-time employment very attractive to women and particularly to mothers, but without alerting these women to the fact that many will later desire full-time employment and find the switch difficult. There is, therefore, a strong gender equity argument for removing the barriers to full-time employment documented here for the part-time employed. Similarly, the existence of barriers to reduced hours employment suggests the need for policies to protect the right of parents, or indeed of anyone with responsibilities external to the workplace, to reduce their working time when needed. Note that we are not arguing for a general reduction in working time as a matter of public policy; instead, we call for enhanced opportunities for hours flexibility - among both the full-time and part-time employed.

The HILDA survey was useful for identifying drop ceiling and trap-door floor effects, and replication of these results for nations other than Australia could be informative. Moreover, as the survey continues, we could ascertain whether these effects are becoming stronger or weaker over time. Nonetheless, because it is a household survey, the HILDA cannot be used to relate these practices to particular firms or organizations. For those interested in ameliorating drop ceilings and trap-door floors and thereby facilitating variations in working time over the life course, organizational-level survey data, matched with data from workers, will be required. That task is left for future research. 


\section{REFERENCES}

Bardoel, E. Anne, Phyllis Tharenou, and Douglas Ristov. 2000. "The Changing Composition of the Australian Workforce Relevant to Work-Family Issues.” International Human Resource Issues 1(1):58-77.

Batt, Rosemary, and P. Monique Valcour. 2003. "Human Resource Practices as Predictors of Work-Family Outcomes and Employee Turnover.” Industrial Relations 42(April):189220.

Berke, Debra. 2003. "Coming Home Again: The Challenges and Rewards of Home-Based SelfEmployment." Journal of Family Issues 24(May): 513-546.

Blank, Rebecca M. 1994. "The Dynamics of Part-Time Work.” National Bureau of Economic Research Working Paper No. 4911, Washington DC: NBER (March).

Boheim, Rene, and Mark P. Taylor. 2004. "Actual and Preferred Working Hours.” British Journal of Industrial Relations 42(March):149-166.

Buddelmeyer, Hielke, Gilles Mourre and Melanie Ward. forthcoming. "Recent Developments in Part-Time Work in EU Countries: Trends and Policy." In Labor Supply and Incentives to Work in Europe, edited by R. Gomez-Salvador, A. Lamo, P. Petrongolo, M. Ward and E. Wasmar. London: Edward Elgar.

Budig, Michelle J. and Paula England. 2001. "The Wage Penalty for Motherhood.” American Sociological Review 66(April):204-225.

Bourke, Juliet. 2004. "Using the Law to Support Work/Life Issues - The Australian Experience." Journal of Gender, Social Policy and the Law 12(April):19-66.

Costa, Dora. 2000. "The Wage and the Length of the Working Day: From the 1890s to 1991." Journal of Labor Economics 18(January):156-181.

Davis, Edward, and Russell Lansbury. 1998. "Employment Relations in Australia.” In International and Comparative Employment Relations, edited by Greg Bamber and Russell Lansbury. London: Sage.

Drago, Robert. 2000. “Trends in Working Time in the U.S.: A Policy Perspective.” Labor Law Journal 51(April):212-217. and Carol Colbeck. 2003. "Mapping the Terrain of U.S. Colleges and Universities for Faculty and Families.” Final Report to the Alfred P. Sloan Foundation, Labor Studies and 
Industrial Relations, Pennsylvania State University (December). [On-line http://sir.la.psu.edu/workfam/mappingproject.htm] , Yi-Ping Tseng and Mark Wooden. 2004. "Family Structure, Usual and Preferred Working Hours, and Egalitarianism in Australia.” Melbourne Institute Working Paper No. 1/04, University of Melbourne.

Folbre, Nancy. 2001. The Invisible Heart. New York: New Press.

Fullerton, Howard N., Jr. 1999. "Labor Force Participation: 75 Years of Change, 1950-98 and 1998-2025." Monthly Labor Review 122(December):3-12.

Gregory, Robert and Robert Duncan. 1981. "Segmented Labour Market Theories and the Australian Experience of Equal Pay for Women." Journal of Post Keynesian Economics 3(Spring):403-428.

Heckman, James J. 1979. "Sample Selection Bias as a Specification Error." Econometrica 47(January):153-62.

Jacobs, Jerry A. and Kathleen Gerson. 2004. The Time Divide: Work, Family, and Gender Inequality. Cambridge MA: Harvard University Press.

Joint Governments Submission 2000. Safety Net Review - Wages: November 1999 - March 2000. Canberra: Department of Employment, Workplace Relations and Small Business.

Moen, Phyllis, ed. 2003. It's About Time: Couples and Careers. Ithaca NY: Cornell University Press.

Tijdens, Kea G. 2002. “Gender Roles and Labor Use Strategies: Women's Part-Time Work in the European Union." Feminist Economics 8(March):71-99.

Williams, Joan. 1999. Unbending Gender: Why Work and Family Conflict and What to Do About It. New York: Oxford University Press.

Watson, Nicole and Mark Wooden, M 2002. "The Household, Income and Labour Dynamics in Australia (HILDA) Survey: Wave one Survey Methodology.” HILDA Project Technical Paper Series No. 1/02, May (Revised September 2002), Melbourne Institute of Applied Economic and Social Research, University of Melbourne.

Wooden, Mark. 2001. "The Growth in Unpaid Working Time.” Economic Papers 20(March):2944. and Diana Warren 2004. "Non-standard Employment and Job Satisfaction: Evidence from the HILDA Survey.” The Journal of Industrial Relations 46:forthcoming. 
SAMPLE Sizes IN HILDA (UNWEIGHTED) FOR Usual AND DESIRED Hours CATEGORIES

\begin{tabular}{|c|c|c|}
\hline & Men & Women \\
\hline No. employed Wave1 & 3771 & 3358 \\
\hline No. PT employed Wave1 & 548 & 1660 \\
\hline No. FT employed Wave1 & 3223 & 1698 \\
\hline $\begin{array}{l}\text { No. PT employed W1 that wanted 5+ more } \\
\text { hours }\end{array}$ & 217 & 440 \\
\hline $\begin{array}{l}\text { No. PT employed W1 that wanted } 5+\text { more } \\
\text { hours and then got them in W2 }\end{array}$ & 117 & 177 \\
\hline $\begin{array}{l}\text { No. FT employed. W1 that wanted } 5+\text { more } \\
\text { hours }\end{array}$ & 263 & 61 \\
\hline $\begin{array}{l}\text { No. FT employed W1 that wanted } 5+\text { more } \\
\text { hours and then got them in W2 }\end{array}$ & 80 & 13 \\
\hline $\begin{array}{l}\text { No. PT employed W1 that wanted } 5+\text { less } \\
\text { hours }\end{array}$ & 22 & 126 \\
\hline $\begin{array}{l}\text { No. PT employed W1 that wanted } 5+\text { less } \\
\text { hours and then got them in W2 }\end{array}$ & 5 & 24 \\
\hline $\begin{array}{l}\text { No. FT employed W1 that wanted } 5+\text { less } \\
\text { hours }\end{array}$ & 1077 & 725 \\
\hline $\begin{array}{l}\text { No. FT employed W1 that wanted } 5+\text { less } \\
\text { hours and then got them in W2 }\end{array}$ & 385 & 242 \\
\hline
\end{tabular}


APPENDIX TABLE 2

Proportions of Population Part-Time Employed Wave1 Moving to Not-In-EMPloyment WAVE2 BY DESIRED HOURS

\begin{tabular}{lccccc}
\hline \hline & \multicolumn{2}{c}{ Men } & & \multicolumn{2}{c}{ Women } \\
\cline { 2 - 3 } \cline { 5 - 6 } & Unemployed & NILF & & Unemployed & NILF \\
\hline Want 5+ more hours & $4.21 \%$ & $7.01 \%$ & & $4.44 \%$ & $10.88 \%$ \\
Do not want 5+ more hours & $6.05 \%$ & $11.86 \%$ & & $1.67 \%$ & $11.47 \%$ \\
\hline
\end{tabular}

APPENDIX TABLE 3

Proportions of Population Full-Time Employed WAVE1 Moving to Not-IN-EMPloyment WAVE2 BY DESIRED HOURS

\begin{tabular}{lccccc}
\hline & \multicolumn{2}{c}{ Men } & & \multicolumn{2}{c}{ Women } \\
\cline { 2 - 3 } \cline { 5 - 6 } & Unemployed & NILF & & Unemployed & NILF \\
\hline Want 5+ less hours & $1.42 \%$ & $2.22 \%$ & & $0.97 \%$ & $5.66 \%$ \\
Do not want 5+ less hours & $1.92 \%$ & $2.88 \%$ & & $1.83 \%$ & $3.85 \%$ \\
\hline
\end{tabular}

